\title{
Pioglitazone for primary stroke prevention in Asian patients with type 2 diabetes and cardiovascular risk factors: a retrospective study
}

\author{
Yi-Chih Hung ${ }^{1,2,6} \bullet$, Lu-Ting Chiu ${ }^{3,4}$, Hung-Yu Huang ${ }^{5}$ and Da-Tian Bau ${ }^{1,6,7^{*}}$ (1)
}

\begin{abstract}
Background: Studies assessing the efficacy of pioglitazone solely for primary stroke prevention in Asian patients with type 2 diabetes mellitus (DM) and present multiple cardiovascular (CV) risk factors are rare. Thus, we aimed to assess the effect of pioglitazone on primary stroke prevention in Asian patients with type 2 DM without established $\mathrm{CV}$ diseases but with risk factors for $\mathrm{CV}$ diseases.
\end{abstract}

Methods: Between 2000 and 2012, we enrolled patients aged $\geq 18$ years, who were newly diagnosed with type 2 diabetes and had at least one of the following CV risk factors: hypertension and hyperlipidemia. Patients with a history of stroke and those using insulin or glucagon-like peptide-1 agonist for more than 3 months were excluded. Patients were divided into the pioglitazone and non-pioglitazone groups based on their receipt of pioglitazone during the follow-up period. Propensity-score matching (1:1) was used to balance the distribution of the baseline characteristics and medications. Follow-up was terminated upon ischemic stroke development, withdrawal from the insurance system, or on December 31,2013, whichever occurred first. The overall incidence of new-onset ischemic stroke in the two groups was subsequently compared. The subgroup analyses of ischemic stroke were conducted using different baseline features. Additionally, the effect of pioglitazone exposure dose on the occurrence of ischemic stroke was evaluated. Chi square test, Student's $t$-test, competing risk regression models, Kaplan-Meier method, and log-rank test were some of the statistical tests conducted.

Results: A total of 13078 patients were included in the pioglitazone and non-pioglitazone groups. Compared with patients who did not receive pioglitazone, those administered pioglitazone had a lower risk of developing ischemic stroke (adjusted hazard ratio: 0.78; 95\% confidence interval: 0.62-0.95). The subgroup analyses defined by different baseline features did not reveal significant alterations in the observed effect of pioglitazone. Moreover, a significant decreasing trend in ischemic stroke risk with an increase in pioglitazone dose ( $p$-value for trend $=0.04$ ) was observed.

Conclusion: Pioglitazone use decreased the risk of new-onset ischemic stroke in Asian patients with type 2 DM and CV risk factors.

Trial registration number CMUH104-REC2-115-CR4

Keywords: Pioglitazone, Stroke, Asian patient, Type 2 diabetes

*Correspondence: artbau2@gmail.com

${ }^{6}$ Terry Fox Cancer Research Laboratory, China Medical University Hospital,

Taichung, Taiwan

Full list of author information is available at the end of the article

(c) The Author(s) 2020. This article is licensed under a Creative Commons Attribution 4.0 International License, which permits use, sharing, adaptation, distribution and reproduction in any medium or format, as long as you give appropriate credit to the original author(s) and the source, provide a link to the Creative Commons licence, and indicate if changes were made. The images or other third party material in this article are included in the article's Creative Commons licence, unless indicated otherwise in a credit line to the material. If material is not included in the article's Creative Commons licence and your intended use is not permitted by statutory regulation or exceeds the permitted use, you will need to obtain permission directly from the copyright holder. To view a copy of this licence, visit http://creativeco mmons.org/licenses/by/4.0/. The Creative Commons Public Domain Dedication waiver (http://creativecommons.org/publicdomain/ zero/1.0/) applies to the data made available in this article, unless otherwise stated in a credit line to the data. 


\section{Background}

Although the incidence of stroke has decreased in most regions, its incidence has increased in East Asia [1]. Stroke is the third leading cause of death in Taiwan, with ischemic stroke being the most common type [2]. Compared with the non-diabetic population, the risk of stroke is increased in patients with type 2 diabetes mellitus (DM) [3]. Additionally, it is an important contributor to stroke morbidity [2]. Pioglitazone is an oral glucoselowering agent belonging to the drug class known as thiazolidinediones (TZD). Pioglitazone acts as an agonist of the peroxisome proliferator-activated receptor $\gamma$. Treatment with TZD has been demonstrated to reduce neuro-inflammation and improve the survival of neurons and glial cells $[4,5]$. TZD therapy has also been shown to prevent or mitigate the progression of carotid intimamedia thickness, a risk factor for ischemic stroke $[6,7]$. Owing to this property, pioglitazone can exert protective effects on the cerebrovascular system. Currently, pioglitazone is generically available and cost-effective. As a result, it is a more affordable option for cerebrovascular protection. In a subgroup analysis of patients with type $2 \mathrm{DM}$ and previous stroke in the PROactive trial [8], the rate of fatal or non-fatal stroke events was significantly lower in the pioglitazone group than the placebo group (hazard ratio: 0.53 ; event rate $5.6 \%$ in the pioglitazone group vs. $10.2 \%$ in the placebo group, $95 \%$ confidence interval: 0.34-0.85; number needed to treat $=22$ ) [9]. In the IRIS study, which included patients with insulin resistance and recent stroke or transient ischemic attack, a lower incidence of stroke or myocardial infarction (MI) was observed in patients administered pioglitazone [10]. The Juntendo Stroke Prevention study in Insulin Resistance and Impaired glucose Tolerance (J-SPIRIT) study was another randomized trial consisting of 120 patients with impaired glucose tolerance or newly diagnosed DM in Japan, who had experienced a non-disabling ischemic stroke or aTIA [11]. Over a median follow-up period of 2.8 years, treatment with pioglitazone was not significantly associated with a lower risk of recurrent stroke (HR 0.62, 95\%, CI 0.13-2.25, $\mathrm{p}=0.49$ ). Nevertheless, the number of enrolled patients in that study was too small. A meta-analysis of the above three trials demonstrated that treatment with pioglitazone in stroke patients with insulin resistance, prediabetes, and DM was associated with a significantly lower risk of recurrent stroke (HR 0.68, 95\% CI $0.50-0.92, p=0.01$ ) [12]. Data from these studies provide strong evidence to support the use of pioglitazone for secondary stroke prevention, and it is possible that the results could be extended in the future to populations without a history of stroke [13]. Based on real-world data, the effect of pioglitazone on stroke varies according to the different clinical characteristics of patients and the interaction with other glucose-lowering agents [14-18]. A meta-analysis of randomized-controlled trials (RCTs) revealed that pioglitazone reduced the risk of stroke in patients with a history of established cardiovascular (CV) diseases [19]. However, as most patients with type 2 DM do not have established CV diseases, determining whether pioglitazone exerts cerebrovascular benefits in patients without established CV diseases, but present multiple risk factors, particularly those with a higher risk of ischemic stroke (e.g., patients of Asian descent), is crucial. Studies assessing the efficacy of pioglitazone solely for primary stroke prevention in Asian patients with type $2 \mathrm{DM}$ and present multiple $\mathrm{CV}$ risk factors are rare.

Therefore, to investigate the effect of pioglitazone on primary stroke prevention in Asian patients without established $\mathrm{CV}$ diseases, but present risk factors for $\mathrm{CV}$ diseases, we conducted a population-based cohort study using the database of the Taiwan National Health Insurance (NHI) program.

\section{Methods \\ Aim and design}

To assess the effect of pioglitazone on primary stroke prevention in Asian patients with type 2 DM without established CV diseases but with risk factors for CV diseases, we opted to perform a retrospective study using claims data.

\section{Data source}

The Taiwan National Health Insurance Research Database (NHIRD) contains the annual reimbursement claim data from the NHI program, which has been the universal health insurance system in Taiwan since 1996, covering approximately $99 \%$ of the Taiwanese population by 1998 [20]. The Longitudinal Health Insurance Database (LHID), which is a subset of the NHIRD, includes historical claims data for one million subjects who were randomly sampled from the entire insured population from 1996 to 2000. Before the release of data for research, all personal identification data in the LHID were de-identified to protect the privacy of patients by the National Health Research Institute via an anonymized number system, which linked each claimant's demographic information to the LHID. The International Classification of Diseases, Ninth Revision, Clinical Modification (ICD9-CM) is used by the NHIRD to categorize disease diagnoses based on outpatient and inpatient data.

\section{Ethical approval}

This study was approved by the Ethics Review Board of China Medical University (CMUH104-REC2-115-CR4), who waived the need for informed consent based on the retrospective design of the study. 


\section{Study population}

Between 2000 and 2012, we enrolled patients aged $\geq 18$ years, who were newly diagnosed with type 2 diabetes (ICD-9-CM codes 250) and had at least one of the following CV risk factors: hypertension (HTN)(ICD9-CM 401-405) and hyperlipidemia (ICD-9-CM 272). We excluded patients diagnosed with stroke (ICD-9-CM 430-438), type 1 DM (ICD-9-CM 250. $\times 1$ and 250. $\times 3$ ), and gestational diabetes mellitus (GDM) (ICD-9-CM 648.83), using insulin or glucagon-like peptide-1 (GLP1) agonist for more than 3 months; coronary artery disease (CAD) (ICD-9-CM 414.00-414.05, 414.8, and 414.9); and peripheral artery occlusive disease (PAOD) (ICD-9-CM 440.0, 440.2, 440.3, 440.8, 440.9, 443, 444.0, 444.22, 444.8, 447.8, and 447.9); or with a follow-up period of $<0.5$ years. The index day was defined as the date of the first prescription of pioglitazone. The subjects were divided into the pioglitazone and non-pioglitazone groups according to the receipt of pioglitazone during the follow-up period (Fig. 1). By propensity score (PS) matching, each patient without pioglitazone treatment was matched for one pioglitazone-treated patient by age; sex; presence or absence of heart failure (HF) (ICD-9-CM codes 428), arrhythmia (ICD-9-CM codes 427), chronic renal disease (CKD) (ICD-9-CM codes 585), HTN (ICD9-CM codes 401-405), and hyperlipidemia (ICD-9-CM 272); and the administration of anti-hypertensive medication, lipid-lowering agents, anti-platelet agents, and oral glucose-lowering agents. Follow-up was terminated upon hospitalization for ischemic stroke (which was ascertained by the ICD-9-CM codes 433-435 in the first position of the hospital discharge diagnoses), a withdrawal from the insurance system, or on December 31, 2013, whichever occurred first. The overall incidence of new-onset ischemic stroke in the two groups was subsequently compared.

\section{Statistical analysis}

The Chi square test and Student's $t$-test were used to compare the differences in the categorical variables and continuous variables, respectively, between the groups. The incidence rate of an event was estimated using the number of events and person-years. Because all-cause mortality is a competing risk of the primary outcome, we considered all-cause mortality during the follow-up period as a competing risk. The hazard ratio (HR) and

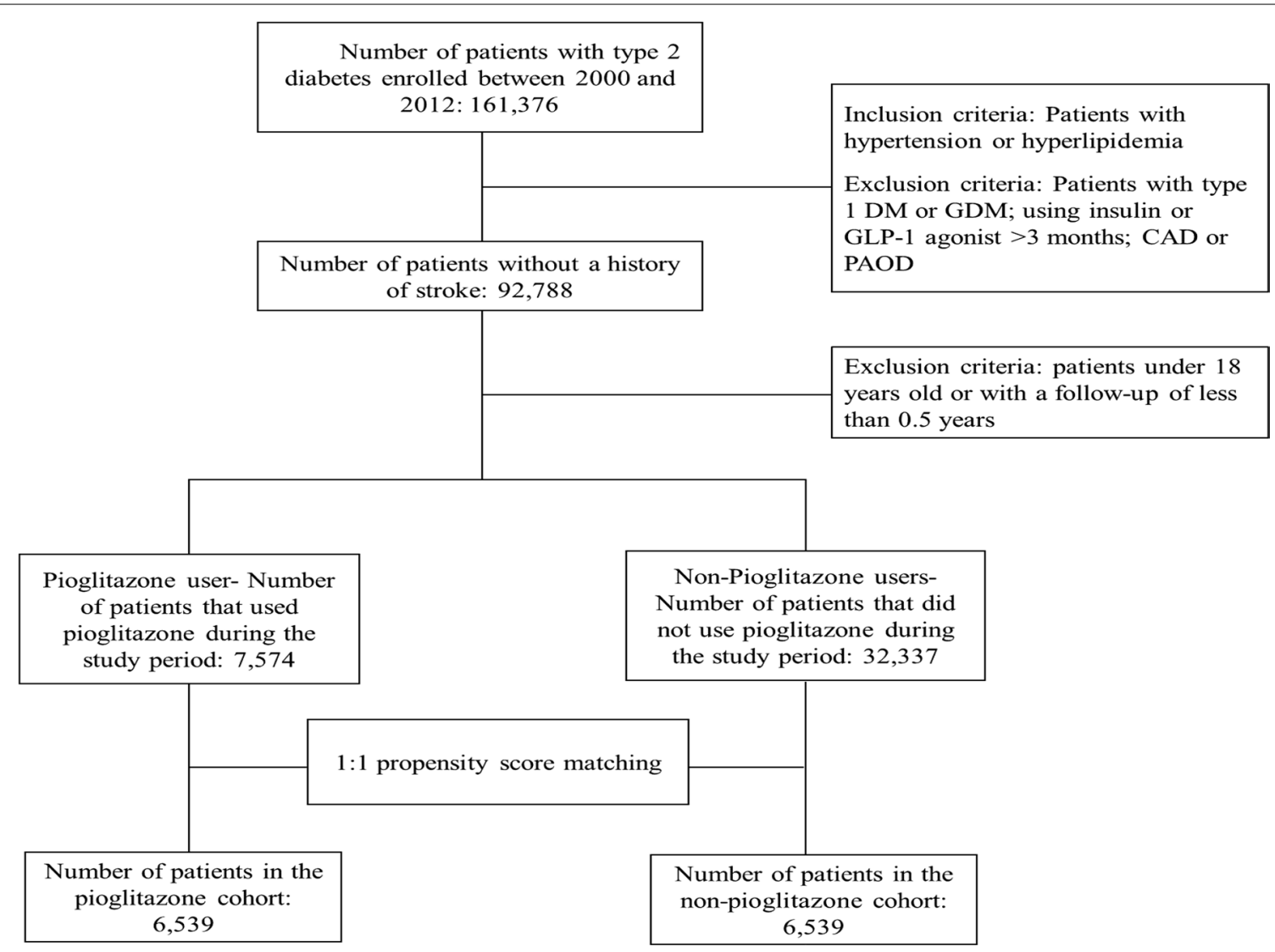

Fig. 1 Flow chart for cohort selection 
95\% confidence interval (CI) for the risk of events were estimated using univariate and multivariate competing risk regression models. The multivariate model was adjusted for age, sex, comorbidities, and the medications listed in Table 1. Subgroup analyses of new-onset ischemic stroke were conducted with 10 pre-specified subgroup variables, namely, age, sex, HF, arrhythmia, CKD, HTN, hyperlipidemia, number of CV risk factors, number of anti-hypertensive agents, and number of glucose-lowering agents. We used the defined daily dose (DDD) per year to quantify the average dose of pioglitazone. Based on DDD, we established the following four categories of dose exposure: no exposure, low dose exposure ( $<100$ DDD per year), intermediate dose exposure (100-250 DDD per year), and high dose exposure (>250 DDD per year) to evaluate the effect of exposure dose on the occurrence of ischemic stroke. The cumulative incidence of new-onset ischemic stroke was assessed using the Kaplan-Meier method and differences between groups were determined using a log-rank test. All statistical analyses were performed using SAS statistical software (Version 9.4 for Windows; SAS Institute, Inc., Cary, $\mathrm{NC}, \mathrm{USA})$. Statistical significance was defined at $\mathrm{p}<0.05$.

\section{Results}

A total of 13,078 patients treated with and without pioglitazone were matched in a 1:1 ratio. The demographic characteristics of the two cohorts were almost similar (Table 1). Most patients were aged $<65$ years and $50 \%$ were males. Approximately $4 \%, 10 \%$, and $10 \%$ of the patients in both cohorts had HF, arrhythmia, and CKD, respectively. Additionally, approximately $74 \%$ and $76 \%$ of patients in the two groups had HTN and hyperlipidemia, respectively. Forty-four percent of the patients had one CV risk factor, whereas $56 \%$ had had two CV risk factors. The number of patients treated with angiotensin-converting-enzyme inhibitor (ACEI), angiotensin receptor blockers (ARB), $\alpha$-blocker, $\beta$-blocker, calcium channel blockers (CCB), diuretics, and other anti-hypertensive agents was similar between the two groups. Approximately 28\%, $20 \%$, and $51 \%$ of patients were treated with $\leq 1,2$, and $\geq 3$ anti-hypertensive agents, respectively. Approximately $56 \%$ of the patients were treated with statin and less than $1 \%$ of the patients in both groups used high-intensity statin. More patients in the pioglitazone cohort used moderate-intensity statin (pioglitazone cohort: $58.76 \%$, non-pioglitazone cohort: $52.84 \% ; \mathrm{p}<0.01$ ), whereas, more patients in the non-pioglitazone cohort used lowintensity statin (pioglitazone cohort: $46.81 \%$, non-pioglitazone cohort: $40.88 \%$; $<20.01$ ). Approximately $35 \%$ of the patients used fibrate, $36 \%$ of whom were also treated with other cholesterol-lowering agents. Approximately $57 \%$ of the patients in both groups used aspirin. Less than
$1 \%, 2 \%$, and $8 \%$ of the patients in both groups used warfarin, clopidogrel, and other anti-platelet agents, respectively. More patients in the non-pioglitazone cohort used sulfonylureas (SU) (pioglitazone cohort: 92.92\%, non-pioglitazone cohort: 94.13\%; $\mathrm{p}=0.01$ ) and more patients in the pioglitazone cohort used $\alpha$-glucosidase inhibitor (pioglitazone cohort: $25.77 \%$, non-pioglitazone cohort: 23.17\%; $\mathrm{p}<0.01$ ) and glinide (pioglitazone cohort: $15.81 \%$, non-pioglitazone cohort: $14.15 \% ; \mathrm{p}=0.01$ ). However, the number of patients who used metformin and dipeptidyl peptidase 4 (DPP4) inhibitors was similar between the two groups. Approximately $13 \%$ of the patients used no more than one glucose-lowering agents and $7 \%$ of the patients in both groups used more than four glucose- lowering agents. More patients in the nonpioglitazone cohort used two glucose-lowering agents (pioglitazone cohort: 51.38\%, non-pioglitazone cohort: $54.46 \%$; $<0.01$ ), whereas more patients in the pioglitazone cohort used three glucose-lowering agents (pioglitazone cohort: $27.65 \%$, non-pioglitazone cohort: $23.98 \%$; $\mathrm{p}<0.01$ ). The mean follow-up duration was $\sim 4$ years in both cohorts, but it was longer in the pioglitazone cohort than in the non-pioglitazone cohort $(4.45 \pm 2.39$ years vs. $4.19 \pm 2.64$ years; $\mathrm{p}<0.01$ ).

As shown in Table 2, the overall incidence of ischemic stroke was 29268 per 1000 person-years in the pioglitazone cohort, a value lower than that found in the nonpioglitazone cohort (27 682 per 1000 person-years), with an adjusted hazard ratio (aHR) of 0.78 (95\% CI 0.62-0.95, $\mathrm{p}=0.03$ ).

The subgroup analyses defined by the different baseline features did not disclose any significant alterations in the observed effect of pioglitazone (Table 3; all p-values for interaction $>0.05$ ).

Compared with non-pioglitazone users, individuals exposed to low-, intermediate-, or high-dose pioglitazone did demonstrate an association, with a 0.79 -fold (adjusted HR 0.79, 95\% CI 0.58-1.06), 0.74-fold (adjusted HR 0.74, 95\% CI 0.53-0.98), and 0.66-fold (adjusted HR $0.66,95 \%$ CI $0.46-0.87$ ) decrease in the risk of ischemic stroke, respectively (Table 4). Moreover, there was a significant decreasing trend of ischemic stroke risk with the increase in pioglitazone dose ( $\mathrm{p}$-value for trend $=0.04$ ).

As shown in Fig. 2, the cumulative incidence of ischemic stroke was significantly lower in the pioglitazone cohort than in the non-pioglitazone cohort (logrank test, $\mathrm{p}=0.01$ ).

\section{Discussion}

Our findings revealed that the use of pioglitazone was associated with a decreased risk of ischemic stroke among Asian patients with type 2 diabetes but present risk factors for $\mathrm{CV}$ diseases. To the best of our 
Table 1 Baseline demographic characteristics of patients with DM treated with and without pioglitazone

\begin{tabular}{|c|c|c|c|c|c|c|c|c|c|c|}
\hline \multirow[t]{3}{*}{ Characteristics } & \multicolumn{4}{|c|}{ Before PS matching } & \multirow[t]{3}{*}{$p$-value } & \multicolumn{4}{|c|}{ After PS matching } & \multirow[t]{3}{*}{$p$-value } \\
\hline & \multicolumn{2}{|c|}{$\begin{array}{l}\text { Non-pioglitazone user } \\
n=32,337\end{array}$} & \multicolumn{2}{|c|}{$\begin{array}{l}\text { Pioglitazone user } \\
n=7574\end{array}$} & & \multicolumn{2}{|c|}{$\begin{array}{l}\text { Non- } \\
\text { pioglitazone } \\
\text { user } n=6539\end{array}$} & \multicolumn{2}{|c|}{$\begin{array}{l}\text { Pioglitazone } \\
\text { user } n=6539\end{array}$} & \\
\hline & $\mathrm{N}$ & $\%$ & $\mathrm{n}$ & $\%$ & & $\mathrm{~N}$ & $\%$ & $\mathrm{n}$ & $\%$ & \\
\hline \multicolumn{11}{|l|}{ Age, years } \\
\hline$<55$ & 12,160 & 37.60 & 2810 & 37.10 & 0.42 & 2302 & 35.2 & 2338 & 35.75 & 0.51 \\
\hline $55-65$ & 8960 & 27.71 & 2463 & 32.52 & $<0.0001$ & 2085 & 31.89 & 2126 & 32.51 & 0.44 \\
\hline$\geq 65$ & 11,217 & 34.69 & 2301 & 30.38 & $<0.0001$ & 2152 & 32.91 & 2075 & 31.73 & 0.15 \\
\hline Mean $\pm S D$ & $59.48 \pm 13.36$ & $59.09 \pm 11.31$ & 0.001 & $59.74 \pm 12.32$ & $59.52 \pm 11.51$ & 0.29 & & & & \\
\hline \multicolumn{11}{|l|}{ Gender } \\
\hline Female & 17,068 & 52.78 & 3801 & 50.18 & $<0.0001$ & 3250 & 49.70 & 3242 & 49.58 & 0.89 \\
\hline Male & 15,269 & 47.22 & 3773 & 49.82 & $<0.0001$ & 3289 & 50.30 & 3297 & 50.42 & 0.89 \\
\hline \multicolumn{11}{|l|}{ Comorbidity } \\
\hline Heart failure & 1920 & 5.94 & 326 & 4.30 & $<0.0001$ & 306 & 4.68 & 296 & 4.53 & 0.68 \\
\hline Arrhythmia & 4686 & 14.49 & 768 & 10.14 & $<0.0001$ & 690 & 10.55 & 695 & 10.63 & 0.89 \\
\hline Chronic kidney disease & 3621 & 11.20 & 788 & 10.40 & 0.05 & 665 & 10.17 & 681 & 10.41 & 0.65 \\
\hline \multicolumn{11}{|l|}{ Vascular risk factor } \\
\hline Hypertension & 21,589 & 66.76 & 5677 & 74.95 & $<0.0001$ & 4863 & 74.37 & 4843 & 74.06 & 0.69 \\
\hline Hyperlipidemia & 21,387 & 66.14 & 5956 & 78.64 & $<0.0001$ & 5003 & 76.51 & 5022 & 76.80 & 0.69 \\
\hline \multicolumn{11}{|l|}{ Number of risk factors } \\
\hline 1 & 18,750 & 57.98 & 3136 & 41.40 & $<0.0001$ & 2899 & 44.33 & 2848 & 43.55 & 0.36 \\
\hline 2 & 13,587 & 42.02 & 4438 & 58.60 & $<0.0001$ & 3640 & 55.67 & 3691 & 56.45 & 0.36 \\
\hline \multicolumn{11}{|l|}{ Drug use } \\
\hline \multicolumn{11}{|l|}{ Hypertensive agents } \\
\hline ACEI & 13,087 & 40.47 & 40.16 & 53.02 & $<0.0001$ & 3382 & 51.72 & 3386 & 51.78 & 0.94 \\
\hline ARB & 7213 & 22.31 & 2727 & 36.00 & $<0.0001$ & 2257 & 34.52 & 2263 & 34.61 & 0.91 \\
\hline a-Blocker & 6744 & 20.86 & 1616 & 21.34 & 0.35 & 1418 & 21.69 & 1418 & 21.69 & 1.00 \\
\hline$\beta$-Blocker & 19,379 & 59.93 & 4498 & 59.39 & 0.39 & 3873 & 59.23 & 3893 & 59.54 & 0.72 \\
\hline $\mathrm{CCB}$ & 13,766 & 42.57 & 3569 & 47.48 & $<0.0001$ & 3154 & 48.23 & 3087 & 47.21 & 0.24 \\
\hline Diuretics & 12,474 & 38.58 & 3045 & 40.20 & 0.009 & 2702 & 41.32 & 2656 & 40.62 & 0.41 \\
\hline Others & 2736 & 8.46 & 538 & 7.10 & 0.0001 & 463 & 7.08 & 475 & 7.26 & 0.68 \\
\hline \multicolumn{11}{|c|}{ Number of hypertensive agents } \\
\hline$\leq 1$ & 10,911 & 33.74 & 2096 & 27.67 & $<0.0001$ & 1809 & 27.66 & 1834 & 28.05 & 0.62 \\
\hline 2 & 7432 & 22.98 & 1561 & 20.61 & $<0.0001$ & 1356 & 20.74 & 13.42 & 20.52 & 0.76 \\
\hline$\geq 3$ & 13,994 & 43.28 & 3917 & 51.72 & $<0.0001$ & 3374 & 51.6 & 3363 & 51.43 & 0.84 \\
\hline \multicolumn{11}{|l|}{ Hypolipidemic agents } \\
\hline Statin & 10,366 & 32.06 & 4506 & 59.49 & $<0.0001$ & 3664 & 56.03 & 3664 & 56.03 & 1.00 \\
\hline \multicolumn{11}{|l|}{ Initial statin therapy } \\
\hline High intensity* & 32 & 0.31 & 16 & 0.36 & 0.01 & 13 & 0.35 & 13 & 0.35 & 1.00 \\
\hline Moderate intensity** & 5418 & 52.27 & 2677 & 59.41 & $<0.0001$ & 1936 & 52.84 & 2153 & 58.76 & $<0.0001$ \\
\hline Low intensity*** & 4916 & 47.42 & 1813 & 40.24 & $<0.0001$ & 1715 & 46.81 & 1498 & 40.88 & $<0.0001$ \\
\hline Fibrate & 6984 & 21.6 & 2805 & 37.03 & $<0.0001$ & 2304 & 35.23 & 2282 & 34.90 & 0.69 \\
\hline Others & 7621 & 23.57 & 2881 & 38.04 & $<0.0001$ & 2397 & 36.66 & 2383 & 36.44 & 0.80 \\
\hline \multicolumn{11}{|l|}{ Anti-platelet agents } \\
\hline Aspirin & 17,438 & 53.93 & 4354 & 57.49 & $<0.0001$ & 3735 & 57.12 & 3723 & 56.94 & 0.83 \\
\hline Warfarin & 320 & 0.99 & 50 & 0.66 & 0.007 & 44 & 0.67 & 47 & 0.72 & 0.75 \\
\hline Clopidogrel & 575 & 1.78 & 178 & 2.35 & 0.001 & 149 & 2.28 & 159 & 2.43 & 0.56 \\
\hline Others & 2644 & 8.18 & 636 & 8.40 & 0.52 & 538 & 8.23 & 551 & 8.43 & 0.68 \\
\hline
\end{tabular}


Table 1 (continued)

\begin{tabular}{|c|c|c|c|c|c|c|c|c|c|c|}
\hline \multirow[t]{3}{*}{ Characteristics } & \multicolumn{4}{|c|}{ Before PS matching } & \multirow[t]{3}{*}{ p-value } & \multicolumn{4}{|c|}{ After PS matching } & \multirow[t]{3}{*}{ p-value } \\
\hline & \multicolumn{2}{|c|}{$\begin{array}{l}\text { Non-pioglitazone user } \\
n=32,337\end{array}$} & \multicolumn{2}{|c|}{$\begin{array}{l}\text { Pioglitazone user } \\
n=7574\end{array}$} & & \multicolumn{2}{|c|}{$\begin{array}{l}\text { Non- } \\
\text { pioglitazone } \\
\text { user } n=6539\end{array}$} & \multicolumn{2}{|c|}{$\begin{array}{l}\text { Pioglitazone } \\
\text { user } n=6539\end{array}$} & \\
\hline & $\mathbf{N}$ & $\%$ & $\mathbf{n}$ & $\%$ & & $\mathbf{N}$ & $\%$ & $\mathbf{n}$ & $\%$ & \\
\hline \multicolumn{11}{|l|}{ Oral antidiabetic agents } \\
\hline Metformin & 10,103 & 31.24 & 6588 & 86.98 & $<0.0001$ & 5610 & 85.79 & 5557 & 84.98 & 0.19 \\
\hline Sulfonylureas & 12,478 & 38.59 & 7111 & 93.89 & $<0.0001$ & 6155 & 94.13 & 6076 & 92.92 & 0.01 \\
\hline DPP4 inhibitors & 569 & 1.76 & 672 & 8.87 & 0.001 & 465 & 7.11 & 499 & 7.63 & 0.26 \\
\hline Alpha-glucosidase inhibitor & 1977 & 6.11 & 2521 & 33.28 & $<0.0001$ & 1515 & 23.17 & 1685 & 25.77 & 0.001 \\
\hline Glinide & 1338 & 4.14 & 1430 & 18.88 & $<0.0001$ & 925 & 14.15 & 1034 & 15.81 & 0.01 \\
\hline \multicolumn{11}{|c|}{ Number of oral antidiabetic agents } \\
\hline$\leq 1$ & 23,544 & 72.81 & 893 & 11.79 & $<0.0001$ & 896 & 13.70 & 893 & 13.66 & 0.94 \\
\hline 2 & 6553 & 20.26 & 3418 & 45.13 & $<0.0001$ & 3561 & 54.46 & 3360 & 51.38 & 0.0004 \\
\hline 3 & 1723 & 5.33 & 2411 & 31.83 & $<0.0001$ & 1568 & 23.98 & 1808 & 27.65 & $<0.0001$ \\
\hline$\geq 4$ & 517 & 1.60 & 852 & 11.25 & $<0.0001$ & 514 & 7.86 & 478 & 7.31 & 0.23 \\
\hline Follow-up duration, year & $5.25 \pm 3.19$ & $4.36 \pm 2.36$ & $<0.0001$ & $4.19 \pm 2.64$ & $4.45 \pm 2.39$ & $<0.0001$ & & & & \\
\hline
\end{tabular}

Data are presented as $\mathrm{n}(\%)$ or mean $\pm \mathrm{SD}$

Number of oral glucose-lowering agents used including metformin, sulfonylureas, DPP4 inhibitors, alpha-glucosidase inhibitor, and glinide

$P S$ propensity score, $A C E l$ angiotensin-converting-enzyme inhibitor, $A R B$ angiotensin receptor blockers, $C C B$ calcium channel blockers

* High-intensity statins: atorvastatin $\geq 40 \mathrm{mg} /$ day, or rosuvastatin $\geq 20 \mathrm{mg} / \mathrm{day}$

** Moderate-intensity statins: $10 \mathrm{mg} /$ day $\leq$ atorvastatin $<40 \mathrm{mg} /$ day, $5 \mathrm{mg} /$ day $\leq$ rosuvastatin $<20 \mathrm{mg} /$ day, $20 \mathrm{mg} /$ day $\leq$ simvastatin, pravastatin $\geq 40 \mathrm{mg} /$ day, lovastatin $\geq 40 \mathrm{mg} /$ day and fluvastatin $\geq 80 \mathrm{mg} /$ day

*** Low-intensity statins: atorvastatin $<10 \mathrm{mg} /$ day, rosuvastatin $<5 \mathrm{mg} /$ day, simvastatin $<20 \mathrm{mg} /$ day, pravastatin $<40 \mathrm{mg} /$ day, lovastatin $<40 \mathrm{mg} /$ day, and fluvastatin $<80 \mathrm{mg} /$ day

Table 2 Hazard ratios and $95 \%$ confidence intervals of ischemic stroke owing to pioglitazone use

\begin{tabular}{|c|c|c|c|c|c|c|c|}
\hline \multirow[t]{2}{*}{ Variables } & \multicolumn{3}{|c|}{ Ischemic stroke $(\mathrm{n}=306)$} & \multirow[t]{2}{*}{ Crude HR $(95 \% \mathrm{Cl})$} & \multirow[t]{2}{*}{ p-value } & \multirow[t]{2}{*}{ Adjusted HR (95\% Cl) } & \multirow[t]{2}{*}{$\mathrm{p}$-value } \\
\hline & Event & PY & $\mathbf{I R}$ & & & & \\
\hline \multicolumn{8}{|c|}{ Pioglitazone } \\
\hline No & 170 & 27,682 & 6.14 & 1 (reference) & & 1 (reference) & \\
\hline Yes & 136 & 29,268 & 4.65 & $0.75(0.60-0.90)^{* *}$ & 0.009 & $0.78(0.62-0.95)^{*}$ & 0.03 \\
\hline
\end{tabular}

HR adjusted for age, sex, heart failure, arrhythmia, chronic kidney disease, hypertension, hyperlipidemia, hypertensive agents, lipid-lowering agents, anti-platelet agents, and oral glucose-lowering agents

$P Y$ person-years, IR incidence rate, per 1000 person-years, $H R$ hazard ratio, $C l$ confidence interval, $P Y$ person-year, $I R$ incidence rate, per 1000 person-years, $H R$ hazard ratio, $\mathrm{Cl}$ confidence interval

${ }^{*} \mathrm{p}<0.05,{ }^{* *} \mathrm{p}<0.01$

knowledge, this is the first study to assess the efficacy of pioglitazone for primary stroke prevention alone in Asian patients with type $2 \mathrm{DM}$ and no established CV diseases, but present risk factors for CV diseases.

Although pioglitazone is now generically available and more cost-effective than a sodium-glucose cotransporter 2 (SGLT2) inhibitor or a GLP-1 receptor agonist for $\mathrm{CV}$ protection, more clinical data may be needed to support the protective effects of pioglitazone against stroke in patients with type $2 \mathrm{DM}$ and no established $\mathrm{CV}$ diseases. To date, RCTs assessing the effect of pioglitazone on primary stroke prevention in these patients are lacking. In 2006, the CHICAGO study (Carotid Intima-Media Thickness in Atherosclerosis Using Pioglitazone) revealed that pioglitazone slowed the progression of CIMT over an 18-month treatment period in patients with type $2 \mathrm{DM}$ and no prior CV disease compared with glimepiride [21]. In 2017, the Thiazolidinediones or Sulfonylureas Cardiovascular Accidents Intervention Trial (TOSCA.IT) was conducted with patients aged 50-75 years with inadequately controlled type 2 DM 
Table 3 Hazard ratios and $95 \%$ confidence intervals of ischemic stroke stratified by age, sex, and comorbidities between the pioglitazone and non-pioglitazone groups

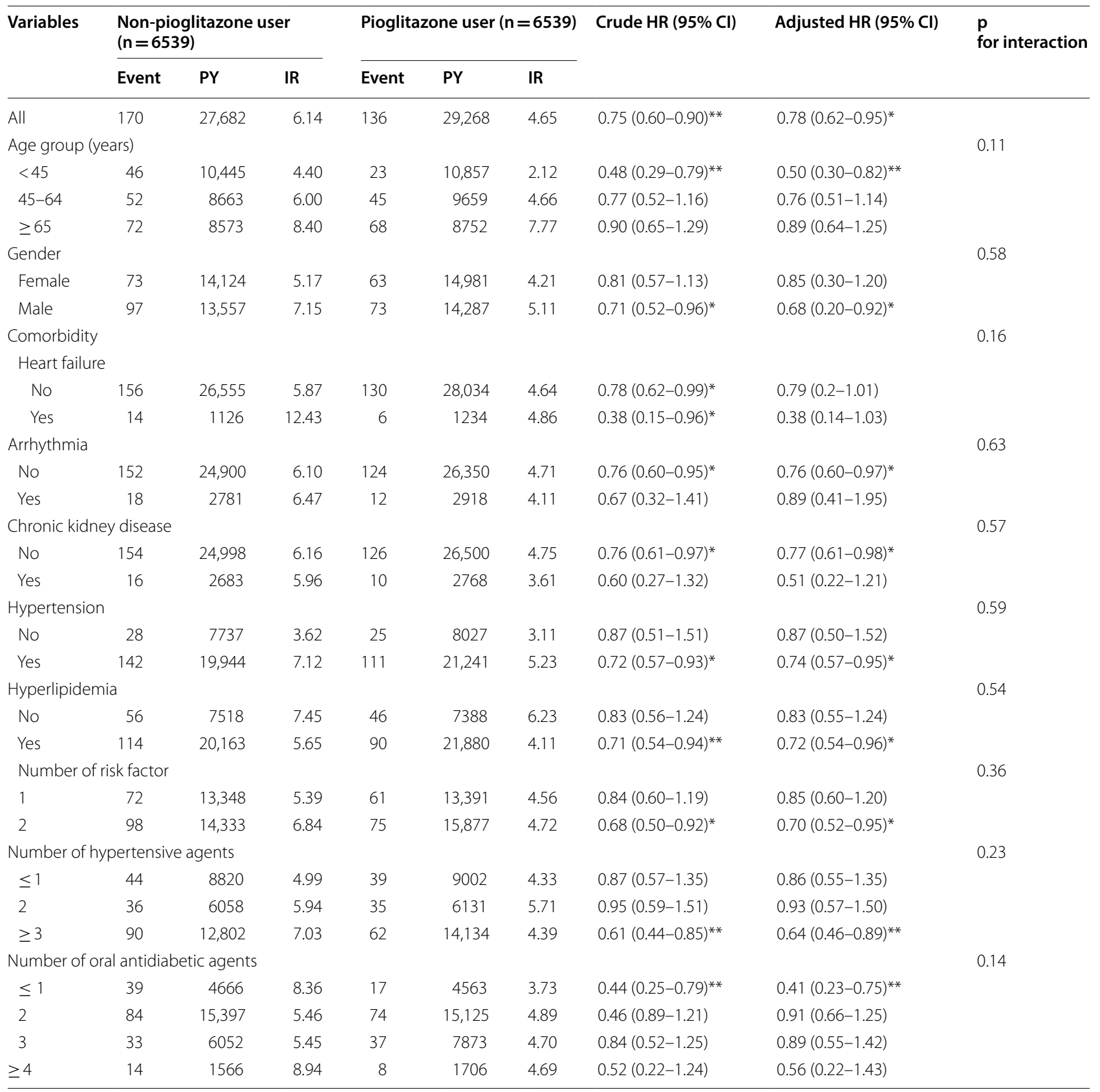

HR adjusted for age, sex, heart failure, arrhythmia, chronic kidney disease, hypertension, hyperlipidemia, hypertensive agents, lipid-lowering agents, anti-platelet agents, and oral glucose-lowering agents

${ }^{*} p<0.05, * * p<0.01$

with metformin monotherapy from 57 diabetes clinics in Italy [22]. Based on the findings, only $11 \%$ of the patients had baseline CV disease and 1-2\% of subjects had a previous stroke. Nonetheless, the incidence of $\mathrm{CV}$ events, including non-fatal stroke, was similar to that with SUs and pioglitazone as add-on treatments to metformin [22]. Considering the large heterogeneity of patients with type $2 \mathrm{DM}$ and the need for a personalized approach, a recent post hoc analysis of TOSCA.IT revealed that men with a urine albumin/creatinine ratio greater than $9 \mathrm{mg} / \mathrm{g}$ and body mass index $>28.8 \mathrm{~kg} / \mathrm{m}^{2}$ presented benefits owing to pioglitazone at an HR of 
Table 4 Hazard ratios and $95 \%$ confidence intervals of ischemic stroke associated with the defined daily doses of pioglitazone

\begin{tabular}{|c|c|c|c|c|c|}
\hline \multirow[t]{2}{*}{ Variables } & \multicolumn{3}{|c|}{$\begin{array}{l}\text { Ischemic stroke } \\
(\mathrm{n}=306)\end{array}$} & \multirow[t]{2}{*}{$\begin{array}{l}\text { Crude HR (95\% } \\
\text { Cl) }\end{array}$} & \multirow[t]{2}{*}{$\begin{array}{l}\text { Adjust HR (95\% } \\
\text { Cl) }\end{array}$} \\
\hline & Event & PY & IR & & \\
\hline \multicolumn{6}{|c|}{ Pioglitazone, DDD (per year) } \\
\hline 0 & 170 & 27,682 & 6.14 & 1 (reference) & 1 (reference) \\
\hline$<100$ & 58 & 12,093 & 4.80 & $0.77(0.57-1.03)$ & $0.79(0.58-1.06)$ \\
\hline $100-250$ & 41 & 8935 & 4.59 & $0.74(0.52-0.95)^{*}$ & $0.74(0.53-0.98)^{*}$ \\
\hline$>250$ & 37 & 8239 & 4.49 & $\begin{array}{c}0.63(0.45- \\
0.84)^{* *}\end{array}$ & $0.66(0.46-0.87)^{*}$ \\
\hline $\mathrm{p}$ for trend & & & & 0.02 & 0.04 \\
\hline
\end{tabular}

HR adjusted for age, sex, heart failure, arrhythmia, chronic kidney disease, hypertension, hyperlipidemia, hypertensive agents, lipid-lowering agents, antiplatelet agents, and oral glucose-lowering agents

${ }^{*} \mathrm{p}<0.05,{ }^{* *} \mathrm{p}<0.01$

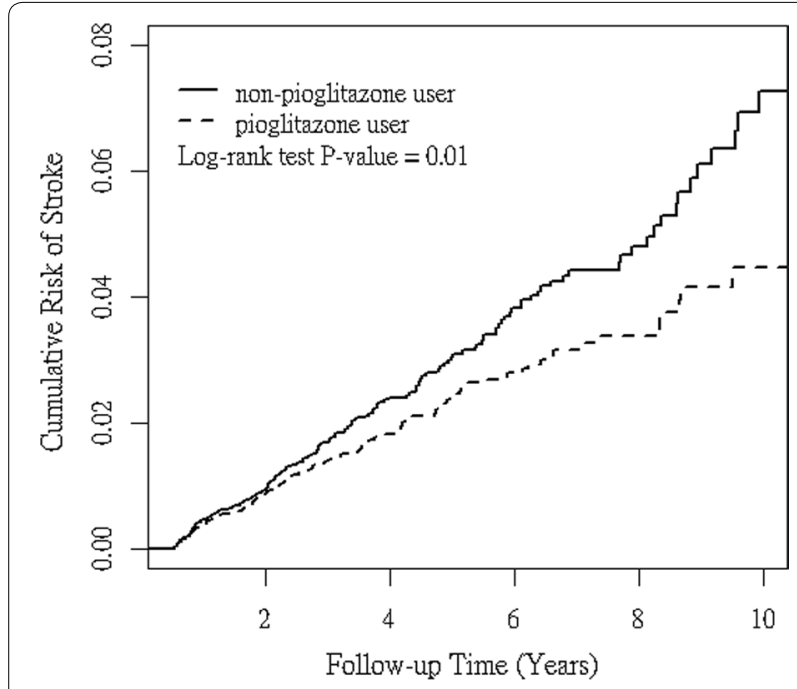

Fig. 2 Cumulative incidence of ischemic stroke in pioglitazone (solid line) and non-pioglitazone (dashed line) users

0.48 (95\% CI, 0.25-0.76) compared with SUs [23]. In Asian patients with type $2 \mathrm{DM}$ without prior $\mathrm{CV}$ diseases, the real-world data demonstrated controversial stroke-protective effects of pioglitazone. Chan et al. [24] demonstrated that compared with sulfonylurea plus metformin, pioglitazone added to metformin therapy may have fewer major $\mathrm{CV}$ events, including ischemic stroke in patients with type $2 \mathrm{DM}$. However, another real-world study conducted by Lu et al. did not reveal the protective effects of pioglitazone on ischemic stroke prevention [25]. These conflicting results may be due to the different clinical characteristics of patients and an interaction with other glucose-lowering agents. In our study, we excluded patients who used insulin or
GLP-1 agonist for more than 3 months and included patients with at least one or more CV risk factors. Moreover, "patients treated with pioglitazone" in our study included those who took pioglitazone during the follow-up period instead of baseline pioglitazone treatment. After PS matching to match all baseline characteristics and adjusting for potential confounders, our study revealed that the use of pioglitazone was associated with a decreased risk of ischemic stroke. Thus, our data provided evidence that pioglitazone could be administered for the primary prevention of ischemic stroke in Asian patients with type $2 \mathrm{DM}$ without prior $\mathrm{CV}$ diseases, but present risk factors for $\mathrm{CV}$ diseases. Defining such a group of patients with a different likelihood of benefitting from pioglitazone treatment represents an important clinical need. Furthermore, this result was similar to the findings of a recent meta-analysis [26] that evaluated the effect of pioglitazone on the primary and secondary prevention of $\mathrm{CV}$ diseases in patients "with or at a high risk" of type 2 DM. In this meta-analysis of 26 RCTs with 19645 participants, although a greater reduction in non-fatal myocardial infarction, non-fatal stroke, or $\mathrm{CV}$ death was noted in patients with a history of established CV diseases than those without, the subgroup differences between the primary and secondary prevention were not statistically significant ( $p$-value for subgroup heterogeneity $>0.05)[26]$.

Previously, the relationship between pioglitazone dose and its protective effect on primary stroke prevention in patients with type $2 \mathrm{DM}$ was unclear. A post hoc analysis of the IRIS study revealed that the HR of recurrent ischemic stroke could be lower in patients in the subgroup with a pioglitazone adherence $\geq 80 \%$ than in those in the intention-to-treat analysis [27]. In our study, there was a significant decreasing trend of ischemic stroke risk with the increasing dose of pioglitazone ( $\mathrm{p}$-value for trend $=0.04$ ). However, it is noteworthy that the use of pioglitazone is difficult to be accepted among measures for the prevention of stroke. This might have derived from the fear of dose-related adverse effects of the drug, such as weight gain and fluid retention [13]. Combination therapy with pioglitazone plus an SGLT2 inhibitor might reduce the frequency of weight gain or edema [28] and beneficial effects of pioglitazone on stroke could additively improve CV outcome when combined with SGLT2 inhibitors [29].

Our study had several strengths. First, the use of an administrative database prevented the under reporting of medical visits. Second, its national population-based design enabled our study to be highly representative of the general population and prevented a selection bias. Third, the risk of misclassification by excluding patients 
who might have had other types of diabetes (patients administered insulin for more than 3 months) was reduced. Fourth, PS matching was employed to match almost all baseline characteristics and adjust for potential confounders during the analysis of the risk of ischemic stroke between pioglitazone and non-pioglitazone users.

Nevertheless, this study had some limitations. First, because this was an observational study, it may be affected by bias and the poor control of confounding factors. Second, the identities of patients were encrypted for privacy and data security reasons. As a result, we could not contact patients to discuss their use of pioglitazone. Third, several potential confounding factors, such as blood pressure (BP), serum glucose level, and lipid panel, were not included in the database. Nonetheless, the number of antihypertensive drugs and oral glucose-lowering agents, and the intensity of initial stain therapy were PS matched to mitigate the bias associated with different levels of BP, blood sugar, and serum lipid between the two groups. Fourth, although experts from the NHI program regularly review randomly selected medical records to confirm the diagnosis from all hospitals, bias may still arise due to miscoding. However, the diagnoses in the NHIRD have previously been validated [30,31]. Finally, as our study included only Taiwanese patients who may have been at a greater risk of developing ischemic stroke due to their Asian descent, our results may not be applicable to other populations.

\section{Conclusions}

In conclusion, the use of pioglitazone was associated with a decreased risk of new-onset ischemic stroke among Asian patients with type 2 diabetes and no established $\mathrm{CV}$ diseases, but present risk factors for $\mathrm{CV}$ diseases. Moreover, there was a significant decreasing trend ischemic stroke risk with the increase in pioglitazone dose. Further studies are thus required to determine the clinical relevance of pioglitazone on the primary prevention of stroke in patients with type $2 \mathrm{DM}$.

\footnotetext{
Abbreviations

DM: Diabetes mellitus; TZD: Thiazolidinediones; MI: Myocardial infarction; RCTs: Randomized-controlled trial; CV: Cardiovascular; NHI: National Health Insurance; NHIRD: National Health Insurance Research Database; LHID: Longitudinal Health Insurance Database; ICD-9-CM: International Classification of Diseases, Ninth Revision, Clinical Modification; HTN: Hypertension; GDM: Gestational diabetes mellitus; GLP-1: Glucagon-like peptide-1; CAD: Coronary artery disease; PAOD: Peripheral artery occlusive disease; PS: Propensity score; HF: Heart failure; HR: Hazard ratio; Cl: Confidence interval; DDD: Defined daily dose; CCB: Calcium channel blockers; SU: Sulfonylurea; DPP4: Dipeptidyl peptidase 4; SGLT2: Sodium-glucose cotransporter 2; TOSCA.IT: Thiazolidinediones or Sulfonylureas Cardiovascular Accidents Intervention Trial; BP: Blood pressure.
}

Acknowledgements

Not applicable.

\section{Authors' contributions}

Y-CH: study design, manuscript writing, data interpretation, revision, and manuscript approval. L-TC: data analysis and interpretation. H-YH: critical discussion. D-TB: manuscript revision and approval. All authors read and approved the final manuscript.

\section{Funding}

This study was supported partially by the Taiwan Ministry of Health and Welfare Clinical Trial Center (MOHW109-TDU-B-212-114004), MOST Clinical Trial Consortium for Stroke (MOST 108-2321-B-039-003-), and Tseng-Lien Lin Foundation, Taichung, Taiwan.

\section{Availability of data and materials}

The Taiwan National Health Insurance Research Database (NHIRD) collects the annual reimbursement claim data from the National Health Insurance program, which has been the universal health insurance system in Taiwan since 1996 (by 1998, the program covered almost 99\% of the Taiwanese population) [20].

\section{Ethics approval and consent to participate}

This study was approved by the Ethics Review Board of China Medical University (CMUH104-REC2-115-CR4). Owing to the retrospective nature of the study, informed consent was waived.

\section{Consent for publication}

Not applicable.

\section{Competing interests}

The authors declare that they have no competing interests.

\begin{abstract}
Author details
${ }^{1}$ Graduate Institute of Clinical Medical Science, China Medical University, Taichung, Taiwan. ${ }^{2}$ Division of Endocrinology and Metabolism, Department of Medicine, China Medical University Hospital, Taichung, Taiwan. ${ }^{3}$ Management Office for Health Data, China Medical University Hospital, Taichung, Taiwan. ${ }^{4}$ College of Medicine, China Medical University, Taichung, Taiwan. ${ }^{5}$ Department of Neurology, China Medical University Hospital, Taichung, Taiwan. ${ }^{6}$ Terry Fox Cancer Research Laboratory, China Medical University Hospital, Taichung, Taiwan. ${ }^{7}$ Department of Bioinformatics and Medical Engineering, Asia University, Taichung, Taiwan.
\end{abstract}

Received: 10 March 2020 Accepted: 8 June 2020

Published online: 20 June 2020

\section{References}

1. GBD 2016 Stroke Collaborators. Global, regional, and national burden of stroke, 1990-2016: a systematic analysis for the Global Burden of Disease Study 2016. Lancet Neurol. 2016;18:439-58.

2. Hsieh Fl, Chiou HY. Stroke: morbidity, risk factors, and care in Taiwan. J Stroke. 2014;16:59-64.

3. Shah AD, Langenberg C, Rapsomaniki E, Denaxas S, Pujades-Rodriguez $\mathrm{M}$, Gale CP, et al. Type 2 diabetes and incidence of cardiovascular diseases: a cohort study in 1.9 million people. Lancet Diabetes Endocrinol. 2015:3:105-13.

4. Perez MJ, Quintanilla RA. Therapeutic actions of the thiazolidinediones in Alzheimer's disease. PPAR Res. 2015;2015:957248.

5. Barbier O, Torra IP, Duguay Y, Blanquart C, Fruchart JC, Glineur C, et al. Pleiotropic actions of peroxisome proliferator-activated receptors in lipid metabolism and atherosclerosis. Arterioscler Thromb Vasc Biol. 2002;22:717-26.

6. Sidhu JS, Kaposzta Z, Markus HS, Kaski JC. Effect of rosiglitazone on common carotid intima-media thickness progression in coronary artery disease patients without diabetes mellitus. Arterioscler Thromb Vasc Biol. 2004;24:930-4.

7. Langenfeld MR, Forst T, Hohberg C, Kann P, Lübben G, Konrad T, et al. Pioglitazone decreases carotid intima-media thickness independently of glycemic control in patients with type 2 diabetes mellitus: results from a controlled randomized study. Circulation. 2005;111:2525-31. 
8. Dormandy JA, Charbonnel B, Eckland DJ, Erdmann E, Massi-Benedetti $\mathrm{M}$, Moules IK, PROactive Investigators, et al. Secondary prevention of macrovascular events in patients with type 2 diabetes in the PROactive Study (PROspective pioglitazone Clinical Trial Inmacro Vascular Events): a randomised controlled trial. Lancet. 2005;366:1279-89.

9. Wilcox R, Bousser M-G, Betteridge DJ, Schernthaner G, Pirags V, Kupfer S, et al. Effects of pioglitazone in patients with type 2 diabetes with or without previous stroke: results from PROactive (PROspective pioglitazone Clinical Trial Inmacro Vascular Events 04). Stroke. 2007:38:865-73.

10. Kernan WN, Viscoli CM, Furie KL, Young LH, Inzucchi SE, Gorman M, et al. Pioglitazone after ischemic stroke or transient ischemic attack. N Engl J Med. 2016;374:1321-31.

11. Tanaka R, Yamashiro K, Okuma Y, Shimura H, Nakamura S, Ueno Y, et al. Effects of pioglitazone for secondary stroke prevention in patients with impaired glucose tolerance and newly diagnosed diabetes: the J-SPIRIT study. J Atheroscler Thromb. 2015;22:1305-16.

12. Lee M, Saver JL, Liao H-W, Lin C-H, Ovbiagele B. Pioglitazone for secondary stroke prevention: a systematic review and meta-analysis. Stroke. 2017;48:388-93.

13. Pantoni L. Potential new horizons for the prevention of cerebrovascular diseases and dementia. JAMA Neurol. 2019;76:521-2.

14. Woo MH, Lee HS, Kim J. Effect of pioglitazone in acute ischemic stroke patients with diabetes mellitus: a nested case-control study. Cardiovasc Diabetol. 2019;18:67.

15. Morgan CL, Inzucchi SE, Puelles J, Jenkins-Jones S, Currie CJ. Impact of treatment with pioglitazone on stroke outcomes: a real-world database analysis. Diabetes Obes Metab. 2018;20:2140-7.

16. Miao S, Dong $X$, Zhang $X$, Jing $S$, Zhang $X$, Xu T, et al. Detecting pioglitazone use and risk of cardiovascular events using electronic health record data in a large cohort of Chinese patients with type 2 diabetes. J Diabetes. 2019:11:684-9.

17. Liu CH, Lee TH, Lin YS, Sung PS, Wei YC, Li YR. Pioglitazone and PPAR- $Y$ modulating treatment in hypertensive and type 2 diabetic patients after ischemic stroke: a national cohort study. Cardiovasc Diabetol. 2020;19:2.

18. Yen FS, Wang HC, Pan CW, Wei JC, Hsu CC, Hwu CM. Pioglitazone exposure reduced the risk of all-cause mortality in insulin-treated patients with type 2 diabetes mellitus. J Clin Endocrinol Metab. 2020;105:dgz026.

19. de Jong $M$, van der Worp HB, van der Graaf $Y$, Visseren FLJ, Westerink J. Pioglitazone and the secondary prevention of cardiovascular disease A meta-analysis of randomized controlled trials. Cardiovasc Diabetol. 2017;16:134.

20. Bureau of National Health Insurance. National Health Insurance Research Database. Taiwan. Zhunan, Taiwan. Bureau of National Health Insurance, Department of Health. http://nhird.nhri.org.tw/en/index.html. Accessed 2015

21. Mazzone T, Meyer PM, Feinstein SB, Davidson MH, Kondos GT, D'Agostino $\mathrm{RB}$, et al. Effect of pioglitazone compared with glimepiride on carotid intima-media thickness in type 2 diabetes: a randomized trial. JAMA. 2006;296:2572-81.
22. Vaccaro O, Masulli M, Nicolucci A, Bonora E, Del Prato, Maggioni AP, Thiazolidinediones Or Sulfonylureas Cardiovascular Accidents Intervention Trial (TOSCA.IT) study group, Italian Diabetes Society, et al. Effects on the incidence of cardiovascular events of the addition of pioglitazone versus sulfonylureas in patients with type 2 diabetes inadequately controlled with metformin (TOSCA.IT): a randomised, multicentre trial. Lancet Diabetes Endocrinol. 2017:5:887-97.

23. Vaccaro O, Lucisano G, Masulli M, Bonora E, Del Prato S, Rivellese AA, TOSCA.IT Investigators, et al. Cardiovascular effects of pioglitazone or sulfonylureas according to pretreatment risk: moving toward personalized care. J Clin Endocrinol Metab. 2019;104:3296-302.

24. Chan CW, Yu CL, Lin JC, Hsieh YC, Lin CC, Hung CY, et al. Glitazones and alpha-glucosidase inhibitors as the second-line oral anti-diabetic agents added to metformin reduce cardiovascular risk in type 2 diabetes patients: a nationwide cohort observational study. Cardiovasc Diabetol. 2018;17:20.

25. Lu CJ, Sun Y, Muo CH, Chen RC, Chen PC, Hsu CY. Risk of stroke with thiazolidinediones: a ten-year nationwide population-based cohort study. Cerebrovasc Dis. 2013;36:145-51.

26. Zhou $Y$, Huang $Y$, Ji X, Wang $X$, Shen $L$, Wang Y. Pioglitazone for the primary and secondary prevention of cardiovascular and renal outcomes in patients with or at high risk of type 2 diabetes mellitus: a meta-analysis. J Clin Endocrinol Metab. 2019;105:dgz252.

27. Spence JD, Viscoli CM, Inzucchi SE, Dearborn-Tomazos J, Ford GA, Gorman $\mathrm{M}$, et al. Pioglitazone therapy in patients with stroke and prediabetes: a post hoc analysis of the IRIS randomized clinical trial. JAMA Neurol. 2019:76:526-35.

28. DeFronzo RA, Chilton R, Norton L, Clarke G, Ryder RE, Abdul-Ghani M. Revitalization of pioglitazone: the optimum agent to be combined with a sodium-glucose co-transporter-2 inhibitor. Diabetes Obes Metab. 2016;18:454-62.

29. Van Baar MJB, van Ruiten CC, Muskiet MHA, van Bloemendaal L, IJzerman RG, van Raalte DH. SGLT2 Inhibitors in combination therapy: from mechanisms to clinical considerations in type 2 diabetes management. Diabetes Care. 2018;41:1543-56.

30. Cheng CL, Lee CH, Chen PS, Li YH, Lin SJ, Yang YH. Validation of acute myocardial infarction cases in the national health insurance research database in Taiwan. J Epidemiol. 2014;24:500-7.

31. Cheng CL, Chien HC, Lee CH, Lin SJ, Yang YH. Validity of in-hospital mortality data among patients with acute myocardial infarction or stroke in National Health Insurance Research Database in Taiwan. Int J Cardiol. 2015;201:96-101.

\section{Publisher's Note}

Springer Nature remains neutral with regard to jurisdictional claims in published maps and institutional affiliations.

Ready to submit your research? Choose BMC and benefit from:

- fast, convenient online submission

- thorough peer review by experienced researchers in your field

- rapid publication on acceptance

- support for research data, including large and complex data types

- gold Open Access which fosters wider collaboration and increased citations

- maximum visibility for your research: over 100M website views per year

At BMC, research is always in progress.

Learn more biomedcentral.com/submissions 